\title{
Olgu sunumu: Dix-hallpike testinde görülen horizontal nistagmuslar hangi semisirküler kanal patolojisini işaret eder?
}

\author{
Case report: Horizontal nystagmus in dix-hallpike test indicate which semicircular canal pathology? \\ DSanem Can Çolak ${ }^{1}$ (DEmre Akgün Özdemir ${ }^{1}$, (D)̈zge Koç ${ }^{1}$, (D)Deniz Uğur Cengiz ${ }^{1}$, (Dismail Demir ${ }^{1}$
}

${ }^{1}$ Inönü Üniversitesi, Sağlık Bilimleri Fakültesi, Odyoloji Bölümü, Malatya, Türkiye

\section{ÖZET}

Benign Paroksismal Pozisyonel Vertigo (BPPV), baş hareketleri ile meydana gelen kısa süreli baş dönmesi ve nistagmuslar ile karakterize periferik vestibüler bir hastalıktır. Pozisyonel tanı testleri uygulanarak provoke edilen nistagmusların karakteristik özelliklerine göre tanı konulur ve tanıya uygun repozisyon manevrası belirlenerek tedavi edilir. Pozisyonel tanı testleri sırasında, değerlendirilen semisirküler kanala ait olmayan yanıtlar elde edilebilmektedir. Bu nedenle nistagmusların karakteristiğini objektif bir test bataryası olan videonistagmografi ile değerlendirmek önemlidir. Pozisyonel tanı testlerinin bütüncül olarak uygulanması ve odyolojik ekipmanların kullanılması tanı sürecinde önemli bir yere sahiptir.

Anahtar kelimeler: benign paroksismal pozisyonel vertigo; Dix-Hallpike testi; Head-Roll testi; nistagmus; videonistagmografi

\section{ABSTRACT}

Benign Paroxysmal Positional Vertigo (BPPV) is a peripheral vestibular disease occurring with head movements and is characterized with shortterm dizziness and nystagmus. The diagnosis is made according to the characteristic features of the nystagmus, which is provoked by applying positional diagnostic tests. It is treated by determining the reposition maneuver suitable for the diagnosis. During the positional diagnostic tests, responses not stemming from the evaluated semicircular canal may be obtained. Therefore, it is important to evaluate the characteristics of nystagmus with videonystagmography, which is an objective test battery. The holistic application of positional diagnostic tests and the use of audiological equipment are important in the diagnosis process.

Keywords: benign paroxysmal positional vertigo; Dix-Hallpike test; Head-Roll test; nystagmus; videonystagmography

\section{Giriş}

Benign Paroksismal Pozisyonel Vetigo (BPPV), 1921 yılında Robert Barany'nin tanımladığı ve kliniklerde en sık karşılaşılan periferik vestibüler rahatsızlıklardan biridir. BPPV, baş pozisyonunun yer çekimine göre değişiklikleri ile tetiklenen, vertigo ve nistagmus ile karakterize olan bir hastalıktır (Bhattacharyya ve ark., 2008). BPPV'nin patofizyolojisini açıklamak için ortaya atılan iki teori vardır. Birinci teori 1962 yılında Schuknecht'in ortaya attığı "kupulolitiazis"tir. Kupulolitiazis teorisine göre, utrikül makulasında yer alan otolitik membrandan serbestleşen otokonyalar, semisirküler kanal kupulasına yapışarak kupulayı lineer hareketlere karşı hassas hale getirerek vertigo oluşturur. İkinci teori ise Hall ve arkadaşlarının tanımladığı "kanalolitiazistir". Kanalolitiazis teorisine göre ise serbestleşen otokonyalar, semisirküler kanal içinde hareket ederek vertigo oluşturur (Roberts \& Gans, 2008).

BPPV'nin doğru bir şekilde tanılanması için pozisyonel tanı testleri uygulanır. Pozisyonel tanı testlerinde elde edilen nistagmusun karakteristik özelikleri, etkilenen semisirküler kanalın tespit edilmesinde belirleyici bir parametredir. Semisirküler kanallardan vertikal kanalların değerlendirilmesi için Dix-Hallpike testi, lateral kanalların değerlendirilmesi için ise Head-Roll testi altın standart testlerdir (McCaslin, 2013). Pozisyonel tanı testleri her ne kadar semisirküler kanalları ayrı ayrı değerlendirse de, hiçbiri semisirküler kanallardan sadece birini tek başına uyarmaz. Başın pozisyon değişikliği ile birlikte tüm semisirküler kanalların yer çekimine göre konumu değişir. Bu nedenle test edilmek istenen semisirküler kanalı provoke edici bir pozisyonda, başka semisirküler kanaldan kaynaklanan nistagmus gözlenebilir. Horizontal kanal BPPV'nin bazen DixHallpike manevrası ile de provoke edildiği bildirilmiştir (Çakir ve ark., 2006; Roberts, 2016). Bununla birlikte horizontal kanal BPPV'nin neden olduğu nistagmusun Dix-Hallpike testine nasıl yansıdığı net değildir.

BPPV, otokonyal debrislerin yeniden utriküle aktarılması esasına dayanan repozisyon manevraları ile tedavi edilir. Tedavi edici manevralar, tanı manevraları esnasında meydana gelen nistagmusların karakteristiklerine göre belirlenir (Lou ve ark., 2020). BPPV'deki nistagmusların karakteristik özelliklerinin doğru bir şekilde tanımlanması için objektif test bataryası olan videonistagmografinin (VNG) klinik önemi büyüktür. Olgu sunumumuzda dış merkezde çıplak gözle değerlendirilerek eksik tanı testleri uygulanan bir hastayı ele aldık. Kliniklerde bütüncül değerlendirmenin ve odyolojik ekipmanların tanıdaki önemini vurgulamayı amaçladık.

\section{Olgu Sunumu}

36 yaşında kadın hasta, baş hareketiyle provoke olan vertigo atakları ile kliniğimize başvurdu. Alınan detaylı anamnezde hasta, daha önce dış merkeze başvurarak tedavi süreci geçirdiğini ancak tedavi sonrasında şikâyetlerinin geçmediğini belirtti. Dış merkezde çıplak gözle Dix-Hallpike testi uygulanarak posterior kanal kanalolitiazis tanısı konulan, Epley manevrası sonrası vestibüler supresan tedavisi alan ve şikâyetleri geçmeyen hasta, kliniğimize başvurdu.

Hastaya yapılan işitsel değerlendirmede işitme eşikleri ve konuşma odyometrisi sonucu normal elde edildi (Şekil 1). 


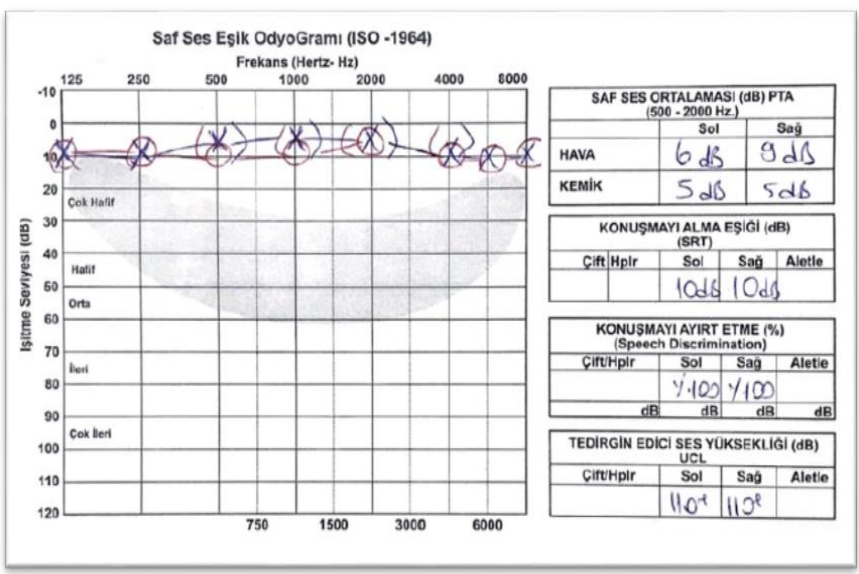

Şekil 1. Saf ses odyometrisi ve konuşma odyometrisi test sonucu
İmmitansmetrik değerlendirmede bilateral Tip A timpanogram gözlendi ve akustik refleksler ipsilateral ve kontralateral olarak pozitif elde edildi.

Hastanın VNG cihazıyla değerlendirilmesinde, gaze testi ve okülomotor test sonuçlarında normal bulgular gözlendi. Spontan nistagmus testinde nistagmus gözlenmedi. DixHallpike testlerinde saf horizontal nistagmus gözlenen hastanın Head-Roll testi sırasında ise ageotropik nistagmus gözlendi. Head-Roll testinde baş sağda iken 21 derece sola çakan, baş solda iken ise 82 derece sağa çakan nistagmus varlığı kupulolitiazisi düşündürürken nistagmusun şiddetine göre patolojik taraf belirlendi (Şekil 2).

Sağ lateral kanal kupulolitiazis BPPV tanısı konulan hastaya tedavi edici manevra olarak Gufoni kupulolitiazis ve hemen ardından Gufoni kanalolitiazis manevraları uygulandı. Üç gün hareket kısıtlaması verilen ve kontrole gelen hastada Dix-Hallpike testinde nistagmus gözlenmedi. Head-Roll testindeki kupulolitiazis formdaki nistagmusların kanalolitiazis forma dönüştüğü ve şiddetinin azaldığı tespit edildi (Şekil 3).

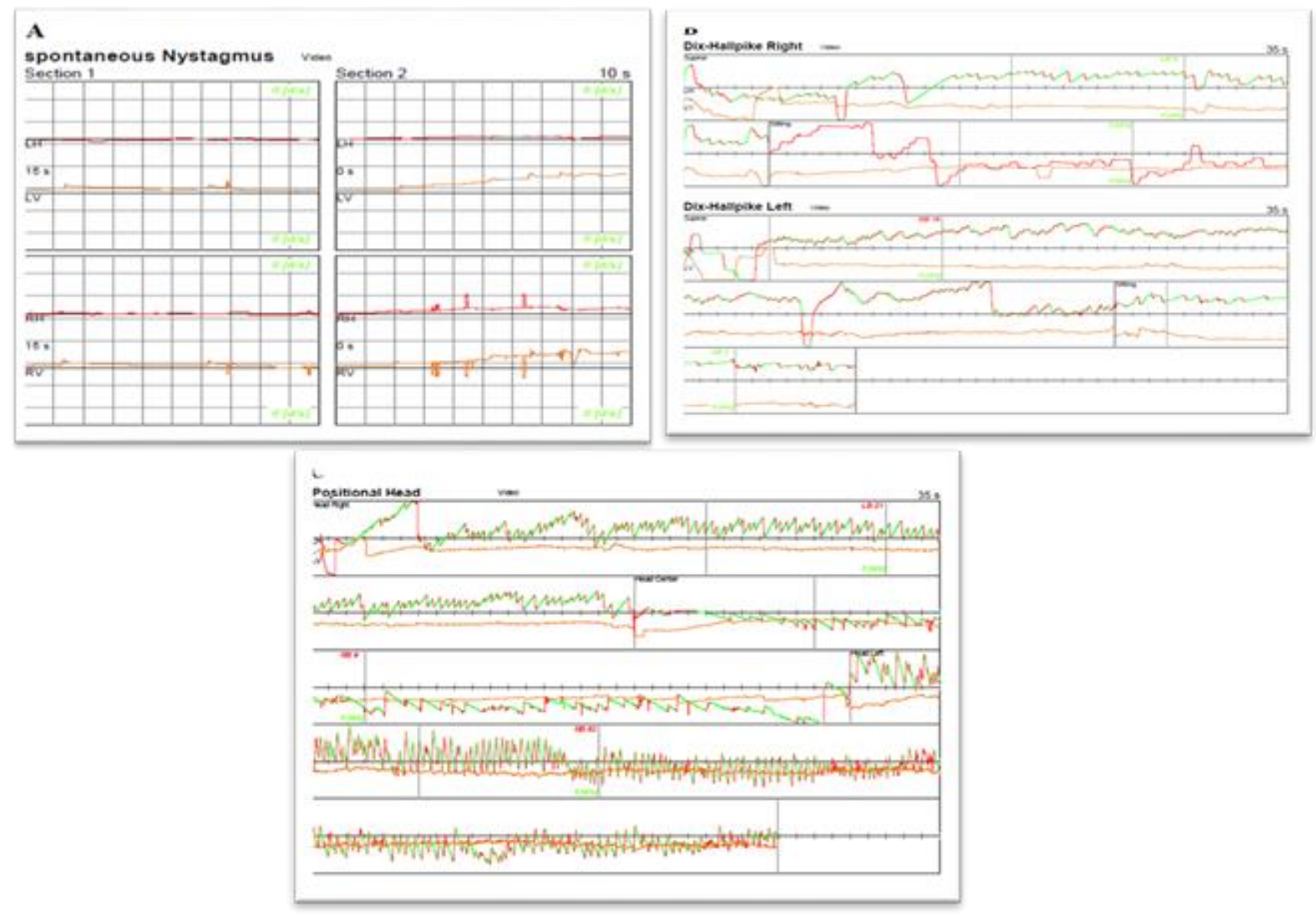

Şekil 2. A. Spontan nistagmus grafiği. B. Dix-Hallpike testinde saf horizontal karakterli nistagmus grafiği. C. Head-Roll testinde ageotropik nistagmus grafiği 
A

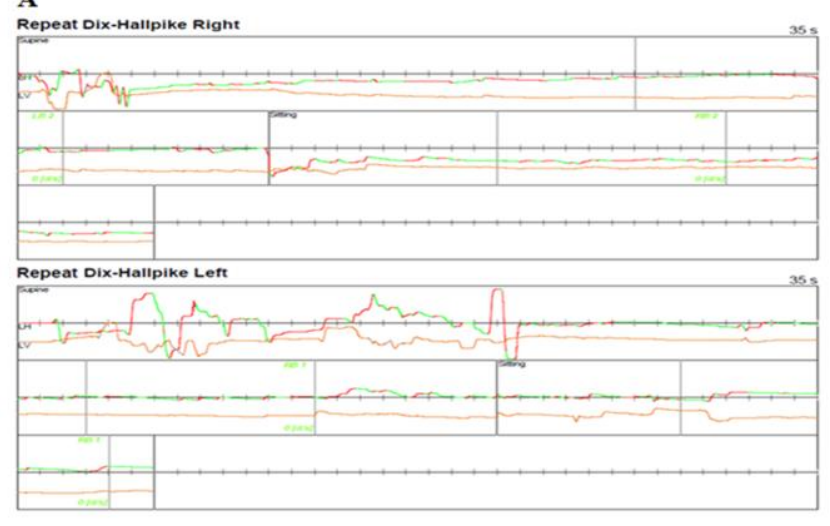

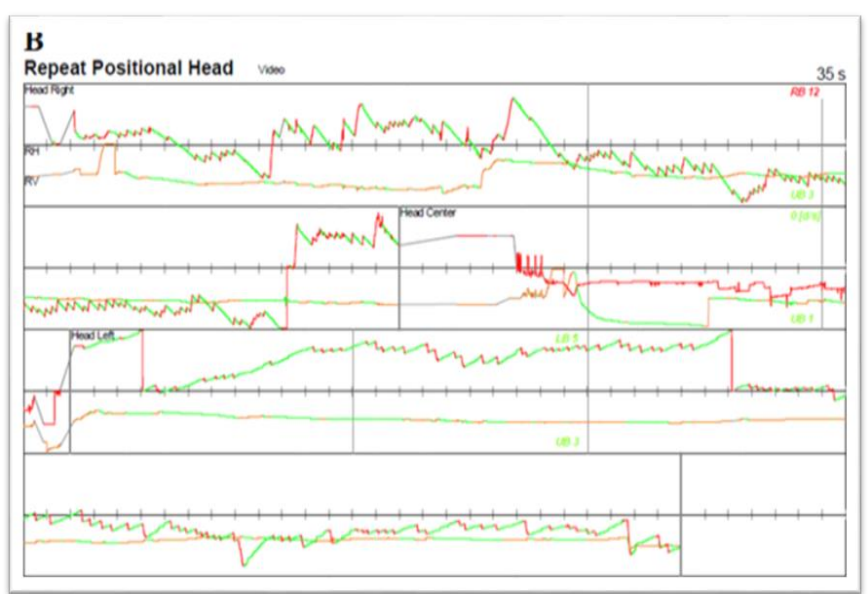

B

Şekil 3. A. Dix-Hallpike testi grafiği. B. Head-Roll testi grafiği

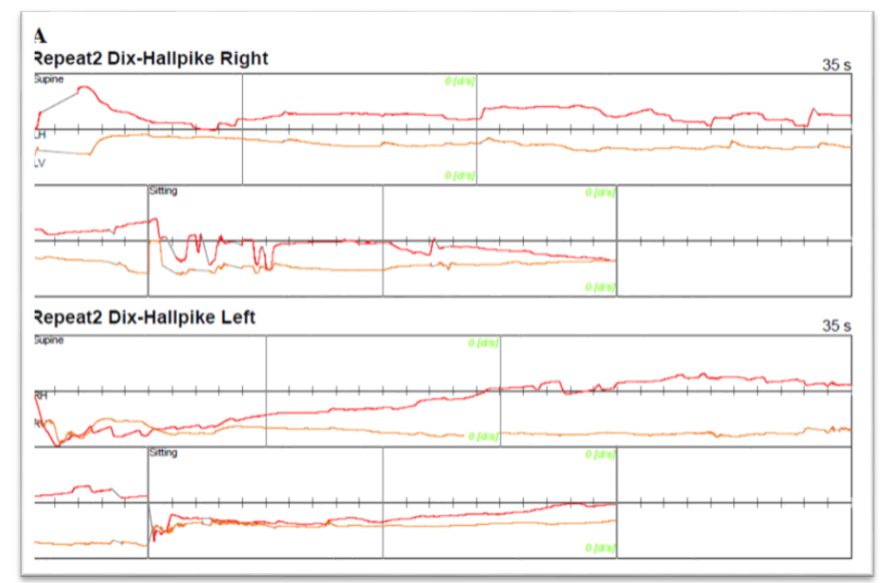

Şekil 4. A. Dix-Hallpike testi grafiği. B. Head-Roll testi grafiği
B

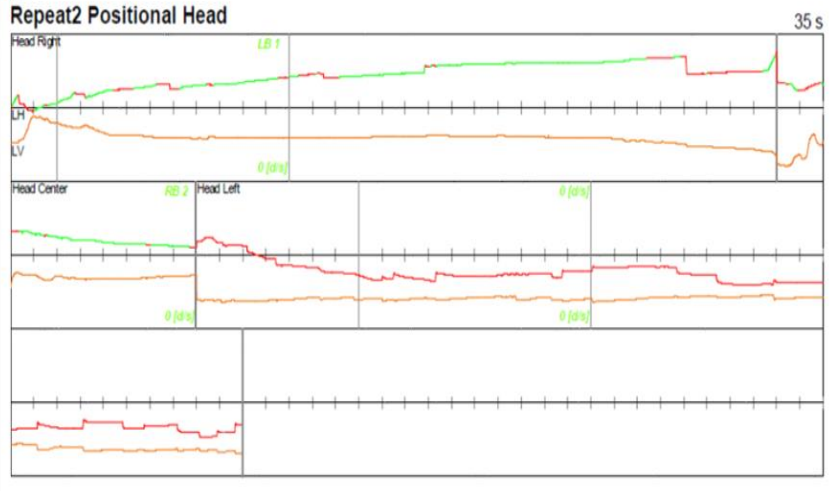

Hastaya tekrar Gufoni kanalolitiazis manevrası uygulandı. Üç gün hareket kısıtlaması verilen ve tekrar kontrole gelen hastada, nistagmusların tamamen kaybolduğu ve hastanın şikâyetlerinin tamamen geçtiği tespit edildi (Şekil 4).

\section{Tartışma}

Vertigonun en yaygın nedeni olarak bilinen BPPV, baş hareketiyle tetiklenen kısa süreli vertigo ve nistagmus ile karakterize periferik bir vestibüler hastalıktır. Özet olarak, otolitik membrandan kopan otokonyaların anterior, posterior veya horizontal semisirküler kanallardan herhangi birinde serbest halde endolenf içerisinde yüzerek veya kupulaya yapışarak kupulada oluşturdukları defleksiyon sonucu gelişir (Brandt \& Steddin, 1993; Lou ve ark., 2020). BPPV'nin posterior semisirküler kanal varyantı, 1952'de tanımlandığından beri iyi bilinen bir durumdur. Dix-Hallpike manevrası ile tetiklenen torsiyonel nistagmus ile karakterizedir (Obrist ve ark., 2016). Buna karşılık, BPPV'nin lateral semisirküler kanal varyantına ilişkin ilk raporlar, Dix-Hallpike testi esnasında 7 hastada geotropik nistagmus gelişmesi sonucu McClure tarafından 1985'te yayınlandı (McClure, 1985). Lateral semisirküler kanal ageotropik nistagmus varyantı ise daha sonraki yıllarda tanımlanmıştır. McClure tarafından lateral kanal kanalolitiazisin ilk olarak Dix-Hallpike testi ile tanımlanması vakamız ile ilişkilidir. Lateral semisirküler kanal BPPV, başın lateral semisirküler kanalın düzleminde konumlandırıması sonucunda hızlı fazı yön değiştiren nistagmuslar ile kendini gösterir ancak lateral semisirküler kanal BPPV'nin Dix-Hallpike testi ile de provoke edildiği bildirilmiştir. BPPV'de pozisyonel nistagmusun, etkilenen kanal düzleminde olduğu bilinmektedir. Ancak tanı manevralarının hiçbiri sadece tek bir kanaldan kaynaklanan yanıtı göstermez. Çünkü baş pozisyonundaki bir değişiklik tüm semisirküler kanalların pozisyonunda değişiklik meydana getirir (Çakir ve ark., 2006; Roberts, 2016)

Bertholon ve arkadaşları 14 hastada Dix-Hallpike testi ile saf horizontal karakterli nistagmus gözlemlediklerini bildirdi. Daha sonra, bu hastalar Head-Roll testi ile değerlendirildiğinde ortaya çıkan nistagmus lateral kanal BPPV ile karakterizeydi (Bertholon, Faye, Tringali, \& Ch, 2002). Benzer olarak, Çakır ve arkadaşlarının yaptığı çalışmada da lateral kanal BPPV'si olan 23 hastanın 9'unda Dix-Hallpike testi ile saf horizontal nistagmus ve vertigo geliştiği bildirilmiştir (Çakir ve ark., 2006). Bizim sunduğumuz olgu da, literatürde bildirilen durumlarla benzer şekilde Dix-Hallpike testinde gözlenen saf horizontal nistagmusların lateral kanal BPPV kökenli olduğunu göstermiştir. Bu nedenle Dix-Hallpike testi esnasında oluşan nistagmusların karakteri çok iyi belirlenmeli ve bütüncül değerlendirme için Head-Roll testi uygulanmalıdır. Lateral 
kanal BPPV Dix-Hallpike testi esnasında provoke olabilir ve nistagmuslar iyi analiz edilmezse bu vakalar vertikal kanal BPPV olarak yanlış teşhis edilebilir (Çakir ve ark., 2006).

Pozisyonel tanı testleri esnasında oluşan nistagmusların yön, latans ve şiddet gibi karakteristik özelliklerinin, VNG kayıt teknikleri ile analiz edilmesi objektif bir değerlendirme imkânı sağlar. BPPV'de tedavi edici manevralar, tanı testlerinde oluşan nistagmusun karakteristiklerine göre belirlendiği için VNG'nin klinik kullanımı büyük önem arz etmektedir. DixHallpike testi esnasında oluşan nistagmusların karakteristiği dikkatli bir şekilde değerlendirilmeli, lateral kanal tutulumunun Dix-Hallpike testine yansıyabileceği unutulmamalıdır. Literatürde spesifik olarak bu konu ile ilgili kısıtlı sayıda çalışmanın olması yansımanın görülme oranını belirlemede yetersiz kalır. Lateral kanal tutulumunun Dix-Hallpike testinde görülme oranını daha net bir şekilde ortaya koyabilmek için geniş çaplı örneklem gruplarıyla prospektif çalışmalara ihtiyaç vardır.

\section{Çıkar Çatışması}

Çalışma kapsamında yazarlar arasında herhangi bir kişisel ve finansal çıkar çatışması rapor edilmemiştir.

\section{Teşekkür}

Olgu sunumumuzda yer alan hastamıza teşekkür ederiz.

\section{Finansal Destek}

Finansal destek bulunmamaktadır.

\section{Bilgilendirilmiş Onam}

Olgu sunumumuzda yer alan hastamızdan onam alınmıştır.

\section{Hakem Değerlendirmesi \\ Dış bağımsız.}

\section{Yazar Katkıları}

S.C.Ç.: Veri Toplama, Literatür Tarama ve Yazım Aşaması E.A.Ö.: Veri Toplama, Literatür Tarama ve Yazım Aşaması Ö.K.: Veri Toplama, Literatür Tarama ve Yazım Aşaması

D.U.C.: Veri Toplama, Literatür Tarama ve Yazım Aşaması

I.D.: Veri Toplama, Literatür Tarama ve Yazım Aşaması

\section{Kaynaklar}

Bertholon, P., Faye, M. B., Tringali, S., \& Ch, M. (2002, April). Benign paroxysmal positional vertigo of the horizontal canal. Clinical features in 25 patients. In Annales D'oto-laryngologie et de Chirurgie Cervico Faciale: Bulletin de la Societe D'oto-laryngologie des Hopitaux de Paris, 119(2), 73-80.

Bhattacharyya, N., Baugh, R. F., Orvidas, L., Barrs, D., Bronston, L. J., Cass, S., . . Fife, T. D. (2008). Clinical practice guideline: benign paroxysmal positional vertigo. Otolaryngology--head and neck surgery, 139(5_suppl), 47-81.

Brandt, T., \& Steddin, S. (1993). Current view of the mechanism of benign paroxysmal positioning vertigo: cupulolithiasis or canalolithiasis? Journal of Vestibular Research: Equilibrium \& Orientation, 3(4), 373-382.

Çakir, B. Ö., Ercan, İ., Çakir, Z. A., Civelek, Ş., Sayin, I.., \& Turgut, S. (2006). What is the true incidence of horizontal semicircular canal benign paroxysmal positional vertigo? Otolaryngology_Head and Neck Surgery, 134(3), 451-454.

Lou, Y., Cai, M., Xu, L., Wang, Y., Zhuang, L., \& Liu, X. (2020). Efficacy of BPPV diagnosis and treatment system for benign paroxysmal positional vertigo. American Journal of Otolaryngology, 41(3), 1-5.

McCaslin, D. L. (2013). Positional and positioning testing. . In Electronystagmography and Videonystagmography. (pp. 105-147). San Diego: CA: Plural.

McClure, J. A. (1985). Horizontal canal BPV. J Otolaryngol, 14(1), 3035.

Obrist, D., Nienhaus, A., Zamaro, E., Kalla, R., Mantokoudis, G., \& Strupp, M. (2016). Determinants for a successful semont maneuver: an in vitro study with a semicircular canal model. Frontiers in Neurology, 7(150), 1-8.

Roberts, R. A. (2016). Technique and Interpretation of Positional Testing. In G. P. Jacobson \& N. T. Shepard (Eds.), Balance Function Assessment and Management. Plural Publishing.

Roberts, R. A., \& Gans, R. (2008). Background, technique, interpretation, and usefulness of positional/positioning testing. In Balance Function Assessment and Management. San Diego, CA: Plural Publishing.171-196. 